\title{
Blockchain in the Implementation of VAT Collection
}

\author{
Georges Bell Bitjoka ${ }^{1}$, Moïse Macaire Nnanga Edoa ${ }^{2}$ \\ ${ }^{1}$ Departement de Télécommunications, National Advanced School of Engineering, University of Yaoundé I, Yaoundé, Cameroon \\ ${ }^{2}$ Departmentof Computer Science, Faculty of Sciencies, University of Yaoundé I, Yaoundé, Cameroon
}

\section{Emailaddress:}

georges@bellbitjoka.com (G. B. Bitjoka), nnangamacaire@gmail.com (M. M. N. Edoa)

\section{Tocite this article:}

Georges Bell Bitjoka, Moïse Macaire Nnanga Edoa. Blockchain in the Implementation of VAT Collection. American Journal of Computer Science and Technology. Vol. 3, No. 2, 2020, pp. 18-26. doi: 10.11648/j.ajcst.20200302.11

Received: April 10, 2020; Accepted: May 5, 2020; Published: May 15, 2020

\begin{abstract}
Tax fraud is the non-payment or the partial payment of taxes by taxpayers through the use of illegal means. This consequences lead to the reduction to the GDP (Gross Domestic Product) of the country. Tax fraud constitutes a curb to the economic development of the country and the blossoming of the population. In Cameroon, the collection of the VAT which means Value Added Tax constitutes the core of interest of this work which is not saved by this illegal practice. The element which favours tax evasion is the fiscal regime from the type declarative most used in the world. The reason why is the most used by states is because it gives a certain freedom to taxpayers. This freedom consists of the taxpayer to declare on the amount of the VAT which he has to deposit to tax authorithies. So, this encourages people to invest in private sectors and also foreign industries to establish in the country. The crowding of these new taxpayers certainly creates employment in the country but does not change the fact that tax invasion is accessible to all taxpayers and the whole by a system instored by the govenment. Optimizing the process of the VAT collection it will come back to secure without violating the rules of the declarative fiscal regime. So, it's about creating a virtual currency known as TVACoin that will have as platform a Blockchain. This currency will permit all payment attach to the VAT. The users who will be concerned by this currency are consumers, taxpayers and tax authorities.
\end{abstract}

Keywords: Secure, Optimize, VAT Collection, Blockchain, Virtual Currency

\section{Introduction}

Value Added Tax (VAT) is an indirect tax that weighs on consumer spending. It is paid for by the final consumer and collected by companies which pass it on to the tax authorities. Regarding this collection of VAT, some companies use illegal techniques not to pass it on to the tax authorities, we talk about tax fraud. Among these techniques, the ones which the tax authorities are most confronted with are the concealment of sales (false amount declared), the concealment of margins (excessive tax increase), declaration of no sale and clandestine sales (unreported sales). In certains countries of Sub-Saharan Africa like Cameroon, the tax evasion is caused by high tax rates, complex and opaque tax laws, inefficient and corrupt tax inspectors, low income of taxpayers, evasion benefits outweighing detection penalties, poor perception of the judicial system and dissatisfaction with the quality and magnitude of public services and goods [14]. This practice has harmful consequences for the functioning of States. Indeed, the government suffers huge loss of revenue. These losses directly affect its debt level and influence its ability to offer services and finance programs that meet the needs of society, which is constantly growing. In addition, the state to carry out its mission who is to satisfying the wants of the general interest, they need means while the tax fraud constitutes brake. It compromises the budgetary balance by reducing collective spending. There are citizens who pay for others. Law-abiding taxpayers find their tax burden unjustly increased because they have to compensate for those who engage in fraud. And this results in non-compliance with the principle of equality before tax. In a market economy, tax fraud undermines the flow of competition. There are taxpayers facing unfair competition because they are lawabiding and aware of their social responsibilities. The statistics of Internation monetary Fund and the report of European Commision on Estimating International Tax Evasion by Individuals in 2019 give us an idea of the illegal enrichment of companies in recent years around the world [15-16].

The Value Added Tax is a tax that is certainly efficient, modern but also complex due to its split payment. The principle of split payment of VAT requires that each company throughout the production chain collects VAT to pay it to the tax authorities. 
The production chain is the set of companies from which a raw material will pass, which will undergo a transformation specific to each company until obtaining a finished product which is sold to the customer. The customer considered as the final consumer, who is responsible for paying VAT [17]. We therefore deduce that the payments and refunds of taxpayers to the tax authorities are linked by the chain of the production of products, ranging from the purchase of the material to the sale of the finished product. Therefore, we have the opportunity to browse the various commercial activities connecting taxpayers in a production chain and thus ensure the proper collection of VAT by the transactions they carry out with each other and with customers. It is therefore a means to set up a virtual currency which will have for platform a Blockchain consortium, flexible enough and adaptable to the needs and context of application. Many organization are interested by the application of Blockchain in the VAT collection, one of them is UE. According to UE, There are a number of reasons why. Blockchain will bring substantial efficiencies to VAT collection. It will reduce costs, and build critical inter-governmental trust relationships. Most importantly, blockchain will immediately end revenue losses well in excess of $€ 50$ to $€ 60$ billion per year in missing trader intra-community fraud (MTIC) [12]. The TVACoin currency will be used for transactions on the commercial activities (sale and purchase) of taxpayers, for the consumption of customers and also for tax activities (payment and refund of VAT to the tax authorities) of taxpayers.

\section{Key Concepts}

\subsection{The Blockchain}

\subsubsection{Definition}

A Blockchain constitutes a distributed transactional database, comparable to a decentralized and shared ledger that stores and transfers value or data via a network in a transparent, secure and autonomous that is, without an agent control. This register is chronological, distributed, verifiable and protected against falsification by a system of trust (consensus) distributed among the members of this network (nodes). Each member of the network has an up-to-date copy of the general register (in almost real time) and the content is always in line with all of the participants [1].

\subsubsection{Principle of Operation}

Transactions between network users are grouped in blocks. Each block is validated by all the nodes of the network by a mechanism called Consensus. There are several types of consensus. The consensus depends on the Blockchain protocol (set of the main rules of a Blockchain). Once the block has been validated, it is time-stamped and added to the blockchain, and it can no longer be removed or modified. Thus the transactions contained in the block can be visible by all or part of the network [1].

\subsection{The Consensus}

Consensus is the method of validation of a Blockchain's block by the nodes of the network precisely by the majority of these nodes, therefore at least $51 \%$ of the nodes. It is also a possibility to make a simple member of the network a node, regardless of the type of Blockchain. It is also used to allow all the nodes to check the validity of the Blockchain itself by retracing the history of the blocks by their timestamp and their hash keys. If the majority of nodes find that a block is not valid then it is not registered on the Blockchain. If a block has been fraudulently inserted into a copy of the Blockchain then the nodes will take care during the verification of the Blockchain to update this copy by deleting the invalid block.

\subsection{VAT Collection Process}

Value Added is the difference between the final value of production and the value of goods and materials that were consumed during the manufacturing process. VAT was invented by French tax specialist Maurice Lauré in 1954. It is an indirect tax that weighs on consumer spending. It is paid by the final consumer and collected by companies which pass it on to the tax authorities [1]. Its indirect nature is linked to the fact that companies collect it at each stage of production and marketing. It is therefore a tax on the split payment and at each stage of the life of the product, only the added value is taxed.

This mechanism is presented as follows:

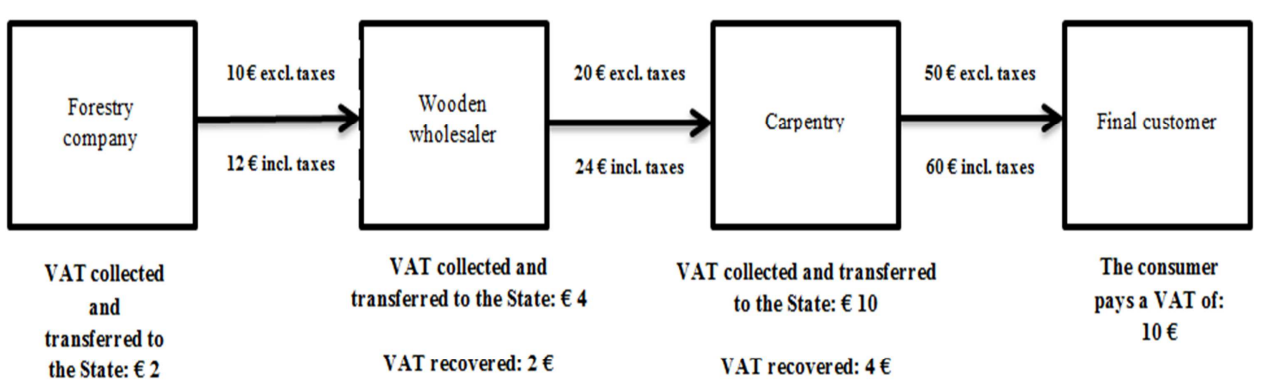

VAT actually collected by the State: $2+4-2+10-4=10 €$

The amount corresponds to the VAT paid by the end customer.

Figure 1. Example illustrating the VAT mechanism. 


\subsection{Tax Fraud}

Tax fraud is a direct and deliberate violation of tax law or an illegal evasion of all or part of the taxable matter. Tax fraud is thus a voluntary hidden of materiels facts to evade tax. It can take several forms of concealment grouped within three categories. Fraud can be material, accounting and legal [10].

\subsubsection{Material Tax Fraud}

It is the most evident form of fraud. We can cite it through an illustration of the concealment of part of the operating equipment to escape proportional rights. It can also correspond to a personal concealment: this is the case of certain trade intermediaries whose working instruments are limited to a telephone, a fax and a computer which are all unknown to the tax authorities [10].

\subsubsection{Accounting Tax Fraud}

It is a high developed form of fraud. For taxes established on declaration, the accounting frequently serves as an instrument of verification for the Administration. Accounting fraud appears to be the classic method of tax fraud. On the ground, several companies tend to practice a double balance sheet: a fiscal balance sheet which is presented to the tax authorities for the establishment of charges and an actual balance sheet which simply traces the reality of operations. However, the tax authorities can cross-check data and detect concealments. This reconstitution of information relates to purchase orders, invoices, delivery notes, bank account statements, cash payment strains, listing of imports and other information received from the company's external partners [10].

\subsubsection{Legal Tax Fraud}

The third form of fraud consists in disguising a factual situation behind an apparently less imposed legal situation. This is the case of sales without invoices collected by the credit of an associated current account assimilating the operation to a loan; or even, deliveries of goods treated as services which will never be collected to avoid payment of VAT. However, the Administration should not remain frozen in the legal qualification of the act presented to it. She must seek the real situation behind the apparent situation. From this point of view, the Administration has several means to detect the exact nature of a transaction or a legal act. The tax authorities can use the right of communication to trace the information back to the source in order to identify the third parties concerned by the transaction and thereby restore the legal nature of the act [10].

\section{Securing of the VAT Collection}

\subsection{The Blockchain of TVACoin}

TVACoin is a cryptocurrency that can be obtained in exchange for a fiat currency from the tax authorities who will be the only ones to create it. It is used for paying VAT and is therefore intended for tax authorities, taxpayers and consumers The transactions are verified and validated by the nodes of the network (all the tax authorities) then recorded in a private ledger (the tax information of a government is mostly confidential) hence the use of a Blockchain Consortium also making it possible to avoid anonymity and pseudonyms in order to have real information on the actors (taxpayers and consumers) who will take part in transactions on the network. A comparative study of the Blockchain Consortium with other types allowed us to develop the following table:

Table 1. Comparative study of the three types of Blockchain.

\begin{tabular}{|c|c|c|c|}
\hline & Public Blockchain & Consortium Blockchain & Private Blockchain \\
\hline The nodes (Decision makers) & $\begin{array}{l}\text { Any participant who agrees with } \\
\text { the consensus method used }\end{array}$ & $\begin{array}{l}\text { Group of participants with an } \\
\text { interest in working together }\end{array}$ & Onenode: The Manager \\
\hline Distribution of the register & To all network participants & $\begin{array}{l}\text { Certain information may be made } \\
\text { public by decision-makers }\end{array}$ & $\begin{array}{l}\text { Only to participants with the } \\
\text { authorization of the Manager }\end{array}$ \\
\hline System type & Decentralized & Decentralized & Centralized \\
\hline Freedom of access & Toeverybody & Toeverybody & $\begin{array}{l}\text { Restricted and requires the } \\
\text { authorization of the Manager }\end{array}$ \\
\hline Pseudonym & Yes & No & No \\
\hline Registration of participants' identity & Non & Yes & Yes \\
\hline Autonomy (Without central control body) & Yes & $\begin{array}{l}\text { No: The group of decision- } \\
\text { makers }\end{array}$ & $\begin{array}{l}\text { No: The central control body is } \\
\text { the Manager }\end{array}$ \\
\hline Transparency & Yes & No & No \\
\hline Direct link between participants & Yes & Yes & No \\
\hline Node reward bonus & Yes & No & No \\
\hline
\end{tabular}

In order to use TVACoins, a user must have a specific address. Upon payment, the latter must digitally sign the transaction with a private key. If this is lost, unlike Bitcoin, the system will use a property recognition mechanism. The consensus algorithm used on this Blockchin will be BFT Raft.

\subsection{The BFT Raft Consensus Algorithm (Byzantin Fault Tolerance Raft)}

The Blockchain consortium has a set of the most widely used consensus algorithms. These vary according to several criteria. A comparative study of the most used of these 
algorithms is presented in the following table:

Table 2. Comparative study of the consensus algorithms of the Blockchain consortium [4].

\begin{tabular}{lllll}
\hline Consensus algorithm & Fault tolerance & Threshold & Confirmation time & Debit \\
\hline Tendermint Core & Byzantine breakdown & $33 \%$ & $5 \mathrm{~s}$ & $10 \mathrm{ktx} / \mathrm{s}$ \\
PBFT & Byzantine breakdown & $33 \%$ & $1 \mathrm{~s}$ & $50 \mathrm{ktx} / \mathrm{s}$ \\
Hashgraph & Byzantine breakdown & $33 \%$ & $1 \mathrm{~s}$ & $100 \mathrm{nodes}$ \\
SCP & Byzantine breakdown & Partitioning & $15 \mathrm{~s}$ & $30 \mathrm{nodes}$ \\
PoET & Byzantine breakdown & No answer & No answer & $1-10 \mathrm{ktx} / \mathrm{s}$ \\
Diversity Mining & Crash & $\leq 50 \%$ & No answer & No answer \\
Raft & Crash & $50 \%$ & $1 \mathrm{~s}$ & $1 \mathrm{ktx} / \mathrm{s}$ \\
\hline
\end{tabular}

From this table, the Raft consensus algorithm is in many ways superior to other consensus algorithms. The simplicity of Raft leads to a number of unique advantages both for educational purposes and as a basis for implementation. Raft assumes that the nodes fail only when stopping, which is rarely the case unfortunately. Malicious attacks and software errors can cause faulty nodes to exhibit Byzantine behavior (they work but return bad information) and, therefore, undermine the accuracy and guarantees of the Raft algorithm. So the BFT Raft algorithm is an improvement of Raft so that it becomes tolerant to the behavior of the Byzantine server. Note that a Byzantine failure is the possibility that a Blockchain node fails its block validation or acts maliciously.

\subsubsection{Raft Algorithm}

i. State of the nodes

To start, Raft declares that each node of a replicated state machine (servers' cluster) can remain in one of the three states, namely, leader, follower and candidate:

Leader - Only the server elected as the leader can interact with the client. All other servers synchronize with the leader.

Follower - The servers (followers) synchronize their data copy with that of the leader after each regular time interval.

Candidate - When contesting an election to choose the leading server, the servers can request votes from the other servers. Therefore, they are called candidates when they have asked for votes. Initially, all the servers are in the Candidate state [5-6].

The system can also be represented as in the image below:

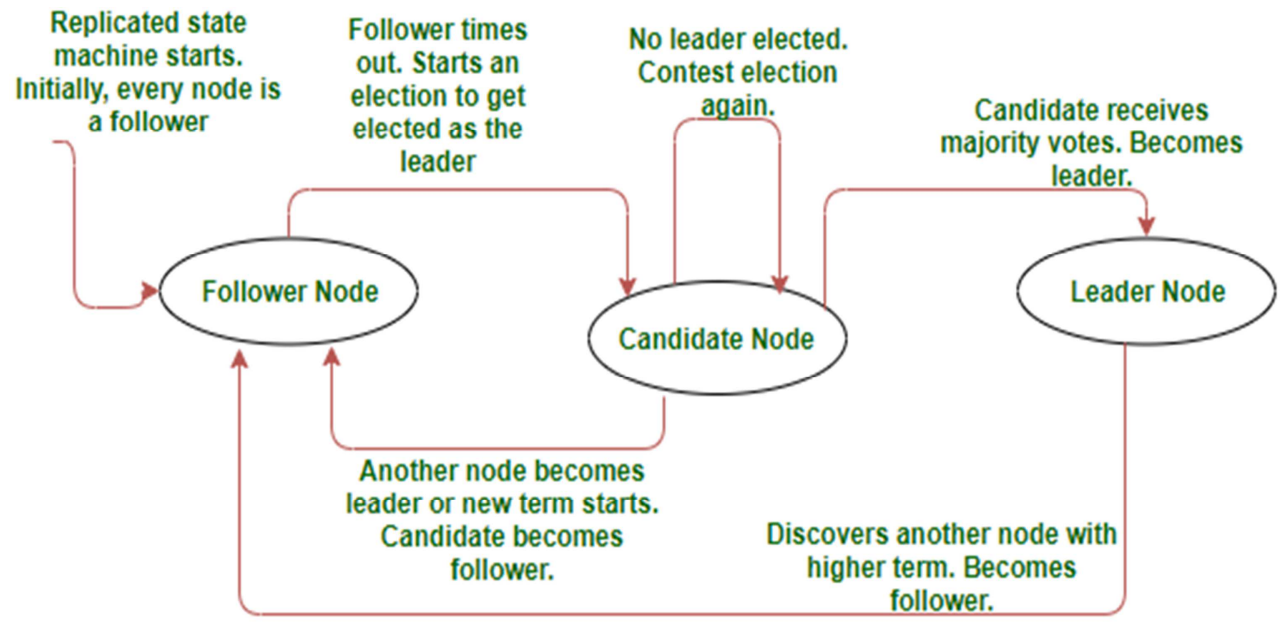

Figure 2. Principle of operation of the Raft algorithm [6].

\section{ii. Term number}

To maintain these server states, the Raft algorithm divides time into small terms of arbitrary length. Each term is identified by a monotonically increasing number, called a term number.

This number is randomly assigned to each node on a value varying from $150 \mathrm{~ms}$ to $300 \mathrm{~ms}$. It constitutes the time necessary for a node to note the absence of a leader and to pass to the state of candidate. Each term begins with an election to determine the new chief. Candidates request votes from other nodes (followers) to obtain the majority. If the majority is met, the candidate becomes the leader of the current mandate. If no majority is established, the situation is called a split vote and the term ends without a leader to make room for a new term. Therefore, a term can have at most one leader. The term number is also randomly assigned to the node over a range of values in order to facilitate the election of a new leader in other words it is the node with the lowest term number value which will be the first to be a candidate and thus quickly win the ways of followers to become a leader [5].

iii. Procedural calls

The Raft algorithm uses two types of remote procedure calls (RPC) to perform the functions:

RPC RequestVotes is sent by candidate nodes to collect votes during an election.

AppendEntries is used by the Leader node to replicate log entries and also as a heartbeat mechanism to check if a server is still in use [5-6].

iv. Election of leader 
In order to maintain authority as the leader of the cluster, the leader node sends a heartbeat to express dominance to the other follower nodes. A leader election takes place when a follower node expires pending a heartbeat from the leader node. At this point, the expired node changes its state to the Candidate state, votes for itself and issues RPC RequestVotes to establish the majority and attempt to become the leader. The election can take the following three forms:

1. The candidate node becomes the leader by receiving the majority of votes from the cluster nodes. At this point, it updates its status to Leader and begins sending heartbeats to notify other servers of the new Leader.
1

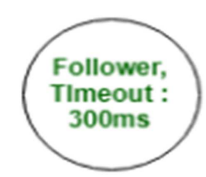

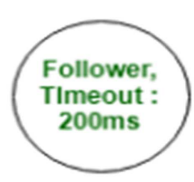

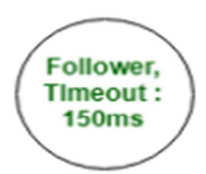

3.

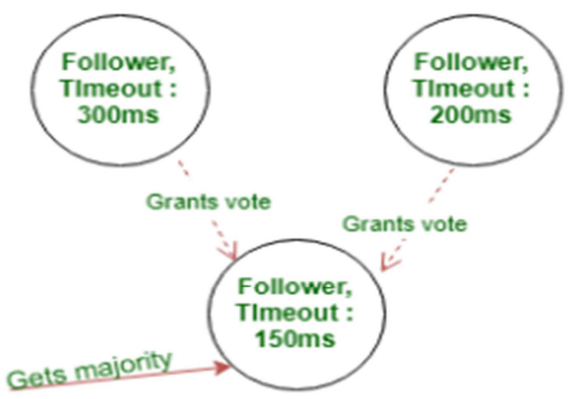

2. The candidate node does not receive the majority of votes during the election and, consequently, the mandate ends without leader. The Candidate node returns to the Follower state.

3 . If the mandate number of the candidate node requesting the votes is lower than that of the other candidate nodes in the cluster, the RPC AppendEntries is rejected and the other nodes retain their candidate status. If the number of mandates is higher, the Candidate node is elected as the new chief [5-6].

The following image simulates a leader election:

2

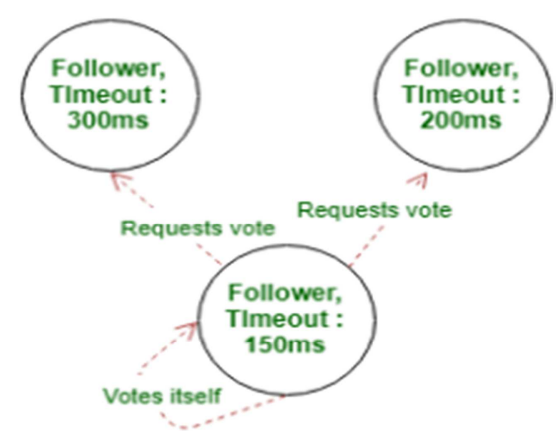

4.
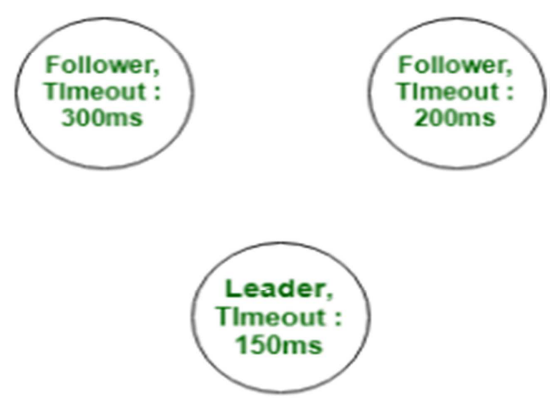

Figure 3. Example of Leader Selection [6].

\subsubsection{From Raft to BFT Raft}

In the design of the BFT Raft algorithm, techniques and decomposition similar to the Raft algorithm were applied in order to preserve its simplicity and comprehensibility, but we use several modifications and additions that provide tolerance to Byzantine failures.

Signature of messages

BFT Raft widely uses digital signatures to authenticate messages and verify their integrity. For example, the leader replicates client messages with client signatures. This prevents a Byzantine leader from modifying the content of the message or falsifying messages. Client public keys are separated from replica public keys to ensure that only clients can send valid new orders and that replicas can send valid Raft RPCs [8].

Customer intervention

BFT Raft allows customers to interrupt current leadership if they fail to progress. This allows BFT Raft to prevent Byzantine leaders from starving the system. [8]

\section{Incremental hashing}

Each replica in BFT Raft calculates a cryptographic hash each time it adds a new entry to its log. The hash is calculated on the previous hash and the newly added log entry. A node can sign its last hash to prove that it has replicated an entire $\log$, and other servers can quickly verify it using signing and hashing [8].

Election verification

Once a node has become a leader, its first RPC AppendEntries to each other node will contain a quorum of RPC RequestVoteResponse that it received in order to become a leader (this is sent before the leader accepts new customer entries). The nodes first check that the leader has actually won an election by counting and validating each of these RequestVoteResponses. Subsequent AppendEntries RPCs in the same term to the same node need not include these votes, but a node can request them in its AppendEntriesResponse if necessary. This will happen if the aftershock restarts and no longer believes that the current leader has won the election for this mandate [8]. 


\section{Validation committee}

In order to validate entries securely during replication, each AppendEntriesResponse RPC is broadcast to each other node, rather than to the leader alone. In addition, each node decides for itself when to increment its validation index, rather than the leader. It does this by keeping track of AppendEntriesResponse RPCs received from other nodes, which are signed and which include the incremental hash of the last log entry for that node. Once a node has received a quorum of matching AppendEntriesResponse RPCs from other nodes to a particular index, it considers this to be the new validation index and rejects all AppendEntriesResponse RPCs stored for previous indexes. This differs from Raft in that the leader no longer has any special responsibility for coordinating commits. The AppendEntriesResponse RPCs approximate the PREPARE message broadcast from PBFT. Each node can verify for itself that a quorum of nodes has prepared up to a particular index and has corresponding entries for this index and all previous indexes by checking the incremental hash [8].

Lazy voters

A node does not grant a vote to a candidate unless he thinks that the current leader is defective. A node comes to believe that its leader is faulty if it does not receive an AppendEntries RPC within its own election time, or if it receives an UpdateLeader RPC from a client for that leader. This prevents nodes that call unnecessary elections from obtaining the votes necessary to become a leader and starve the system. [8]

An implementation of the python code of this algorithm is available on the following link: https://github.com/Gamrix/cs244b_proj [8].

\section{Result and Discussion}

\subsection{Discussion}

\subsubsection{The Strengths of This Work}

We can cite:

The better control of tax activities by tax authorities;

The amelioration of the GDP of a state;

Financial capital necessary for the development of a state;

The non-violation of the declarative fiscal regime for the taxpayers;

The justice and encouragement of decent taxpayers;

The computerization of economic and tax sectors;

Non-falsification of datas;

The solution of a unique currency for tax activities in interstates.

\subsubsection{The Weaknesses of This Work}

We can cite:

For a consumer to make a transaction, he most gives the amount of the VAT which can be difficult for the small consumer;

The set-up of this system may push the enterprises which are wirely engage in the practice of tax invasion to close and so, leading to lost of employment.

\subsection{Result}

In this part we will simulate using figures the use of TVACoin on the VAT collection process by going on the principle that 1 CFA Franc equals 1 TVACoin.

\subsubsection{Purchase of TVACoin by a Taxpayer}

This can be represented in the following way:

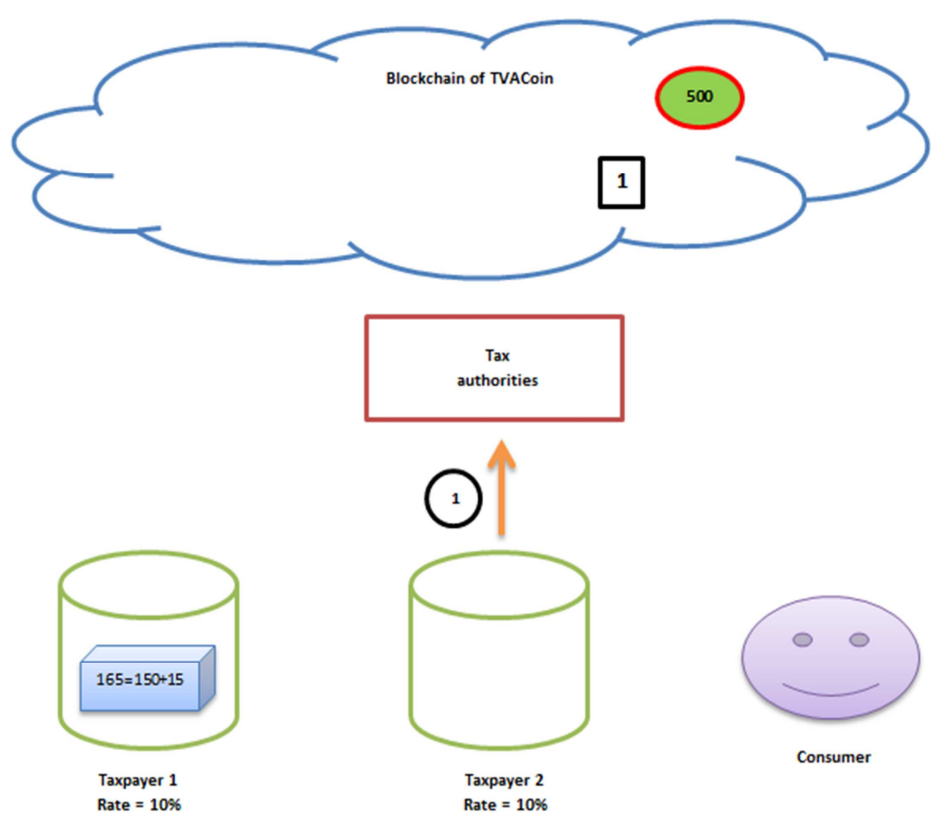

Figure 4. Purchase of TVACoin by a taxpayer.

In this step, taxpayer 2 wishes to buy a product from taxpayer 1. This product is worth 165 CFA francs (all taxes included) for 150 CFA francs (excluding tax) with $15 \mathrm{CFA}$ francs in VAT. Taxpayer 2 through phase 1 therefore submits a request to the tax authorities to buy them a value of 165 TVACoins. Note that the tax authorities are the only ones able to sell and create TVACoin. On the Blockchain, the value 500 represents the total value of VAT in circulation in 
the network. Then the request of the taxpayer 2 which consists of creating 165 TVACoins is recorded in the Blockchain. Note that there are two types of requests. One of them consist the creation of the TVACoin by tax autorithies to sel lit and another request which consists in deleting only the value of the VAT on the Blockchain when paying the VAT to the tax authorities or refunding the VAT to the taxpayers by the tax authorities.

\subsubsection{Collection of VAT from a Taxpayer and Payment of VAT to the Tax Authorities}

This can be represented in the following way:

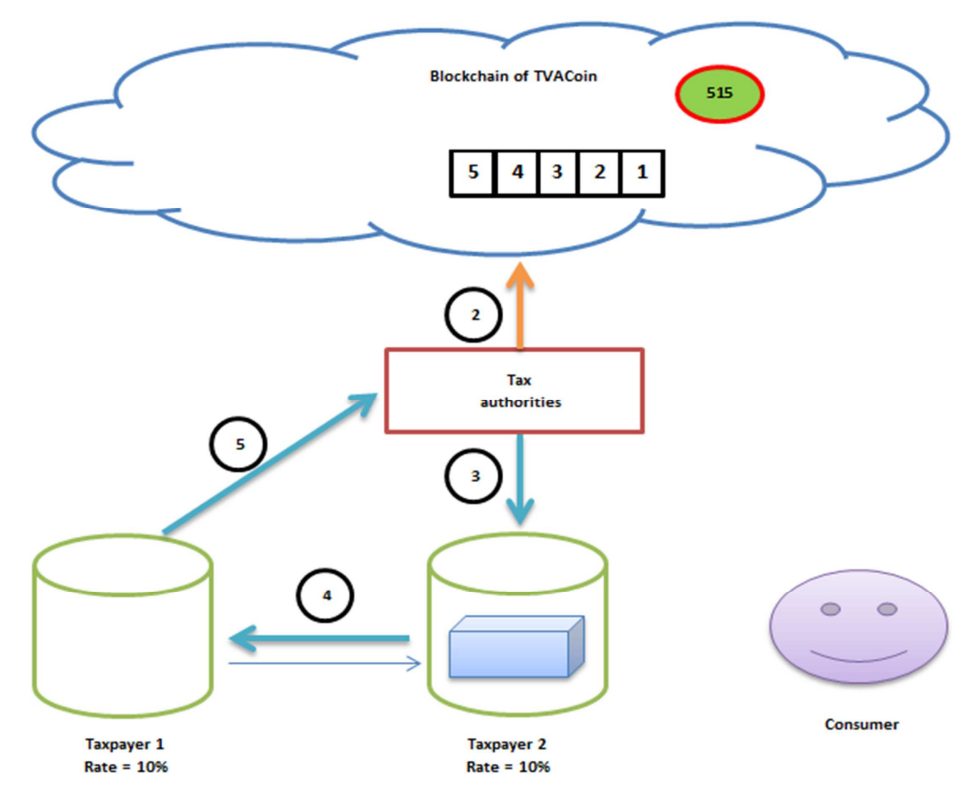

Figure 5. Collection of VAT from a taxpayer and payment of VAT to the tax authorities.

Step 2 consists of the tax authorities creating a value of 165 TVACoins on the Blockchain for an increase of 15 TVACoins on the VAT totality in circulation in the Blockchain, hence the value of 515. Step 3 consists of the sale 165 TVACoins to taxpayer 2 in exchange for an equvalent traditional currency (165 CFA Francs). In step 4 taxpayer 2 purchases the product in question from taxpayer 1 with TVACoin. In step 5, taxpayer 1 transfers to the tax authorities the value of VAT collected during this last transaction, namely 15 TVACoins. All these steps will be recorded in the Blockchain.

\subsubsection{Withdrawal on the Blockchain of the Value of the VAT Paid Back and Purchase of TVACoin by a Consumer}

This can be represented in the following way:

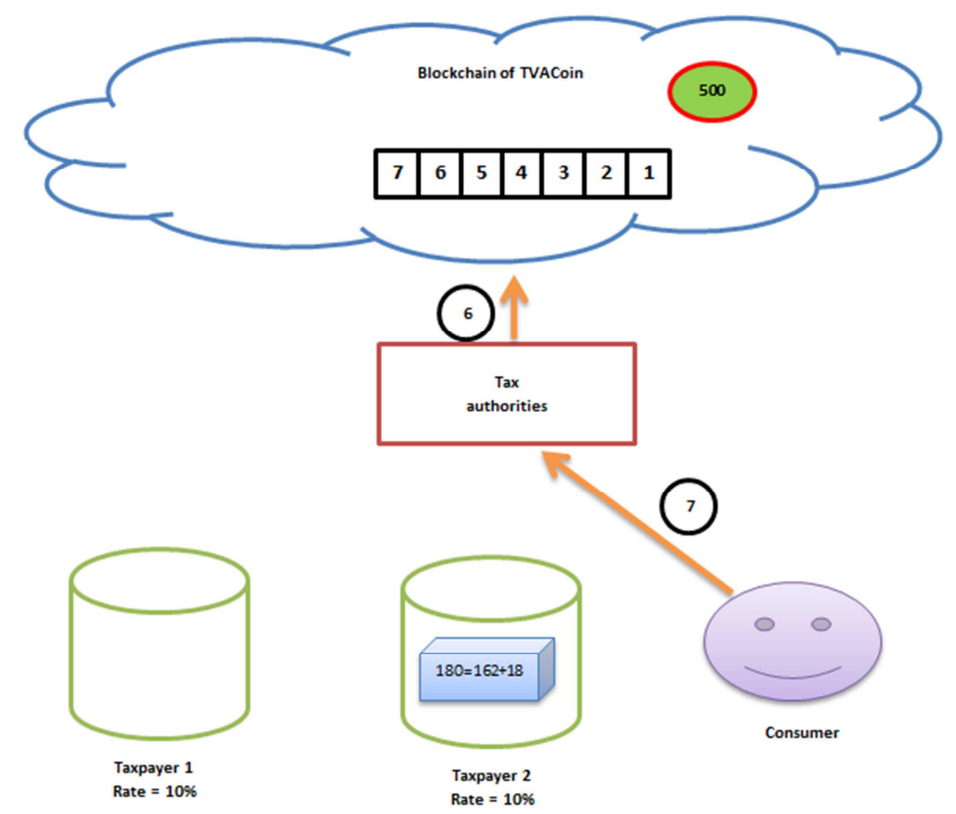

Figure 6. Withdrawal on the Blockchain of the value of the VAT paid back and purchase of TVACoin by a consumer. 
In step 6, the tax authorities withdraw from the Blockchain the value of VAT which has been paid by the taxpayer 1, thus the total value of VAT in circulation in the network returns to 500. A consumer wishes to buy the product from the taxpayer 2. The product costs 180 Francs CFA incl. taxes for 162 Francs CFA excl. taxes with 18 Francs CFA VAT. The consumer therefore makes a request to the tax authorities for the purchase of 180 TVACoins. The two steps are recorded in the Blockchain.

\subsubsection{Collection of VAT from a Consumer and Payment of VAT to the Tax Authorities}

This can be represented in the following way:

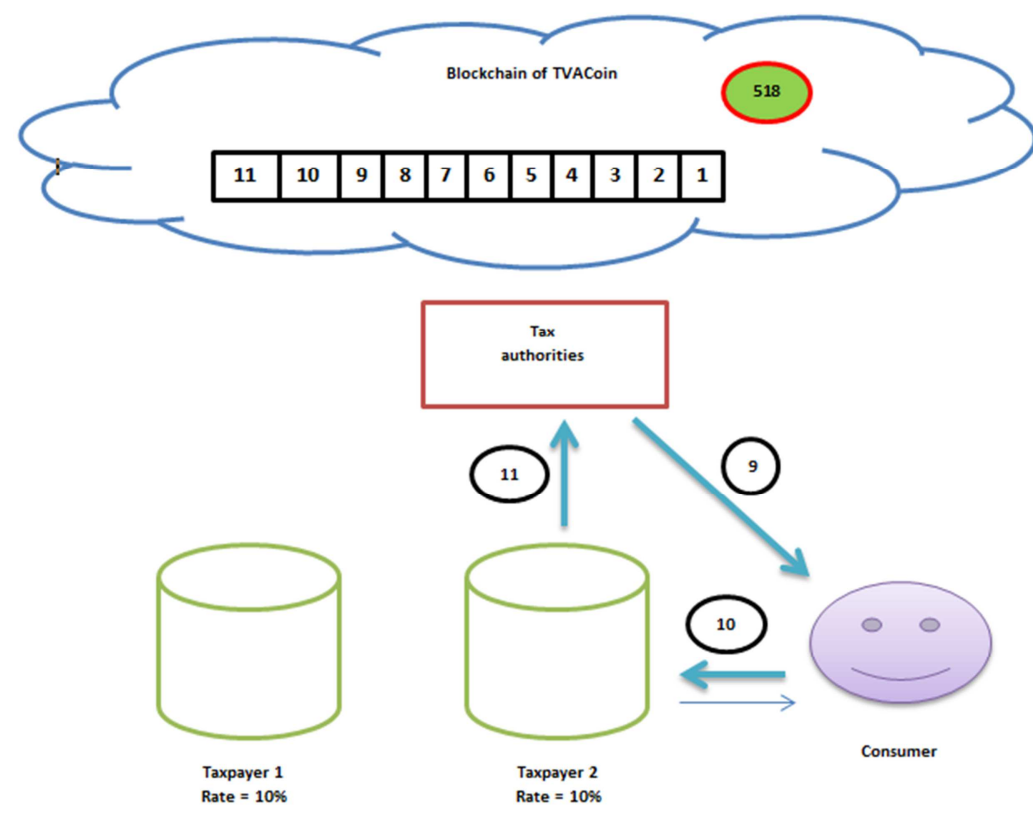

Figure 7. Collection of VAT from a consumer and payment of VAT to the tax authorities.

In phase 9 the tax authorities create a value of 180 TVACoins in the network which they pay back to the consumer in exchange for an equivalent fiduciary currency (180 Francs CFA). Thus the total value of VAT in circulation in the network now equals 518 TVACoins. In phase 10, the consumer purchases the product from taxpayer 2 with TVACoin. This in phase 11, transfers the value of 18
TVAoins of VAT to the tax authorities. All these phases will be recorded on the Blockchain.

\subsubsection{Withdrawal on the Blockchain of the Value of the VAT Transfered and Refundment of the Taxpayer} This can be represented in the following way:

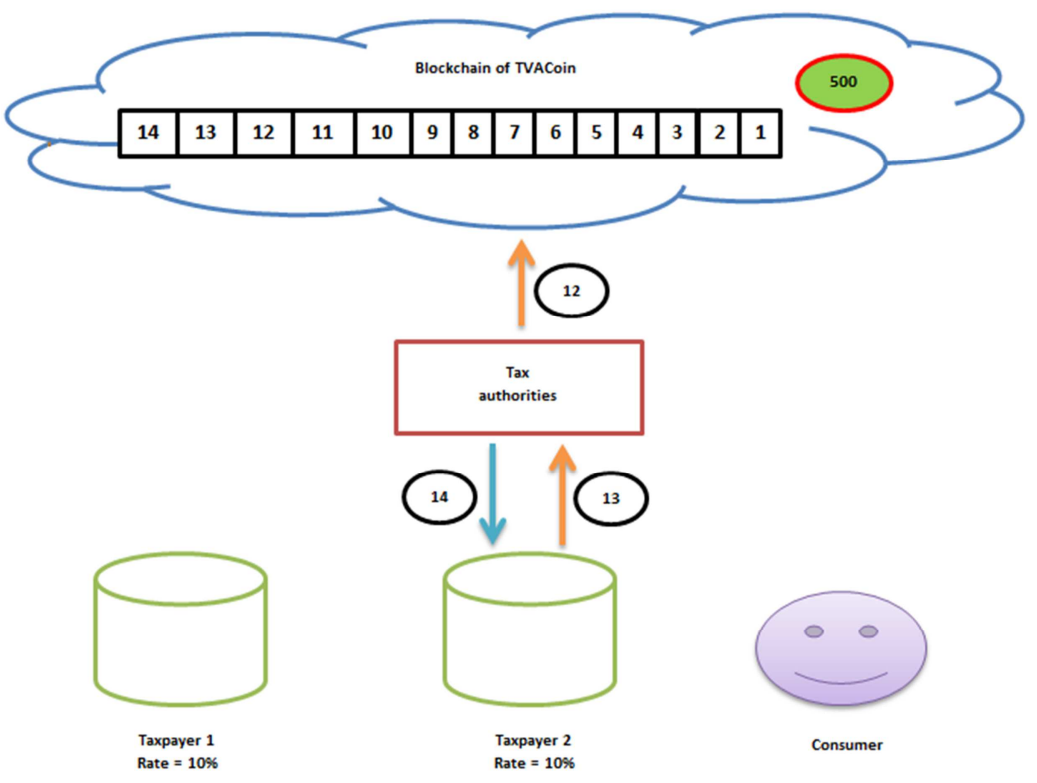

Figure 8. Withdrawal on the Blockchain of the value of the VAT transferred to tax authorities and refundment of the tax payer by tax authorities. 
The VAT once paid by the taxpayer 2, the tax authorities will withdraw the value of it in the network in phase 12 . Thus, the total value of VAT in circulation in the network is 500 TVACoins. The taxpayer 2 in phase 13, in order to recover the VAT paid to the taxpayer 1 for the purchase of a product will issue a request to the tax authorities. Thus, the tax authorities will be able to reimburse that either by traditional money or by TVACoins by proceeding to the creation of a new value on the network. All these phases will be recorded in the Blockchain.

\section{Conclusion and Perspectives}

In this work, we presented a solution to the problem of securing the collection of VAT. This solution consisted in setting up a consortium Blockchain which serves as a platform for virtual money called "TVACoin". The blockchain in question, using one of the most powerful consensus algorithms, namely Raft, improved by a Byzantine fault tolerance to produce the BFT Raft algorithm which is simple, efficient and very understandable. We also presented the functioning of the TVACoin currency by simulating transactions carried out during the VAT collection process which goes from the company which buys the raw material to the customer who is the final consumer and the main payer of the VAT because the companies collect it just for the tax authorities and recover the one they spent on their own purchases. In terms of prospects, it would be interesting to look at international tax activities. Certain tax frauds are specific to international tax activities. We can cite fraud "Carrousel" and "MTIC" (Missing Trader Intra Community). The special report on the fight against intra-community VAT fraud in 2015 estimated 40-60 billion in annual tax revenue losses for the member states of the European Union [7]. The use of a virtual currency could also be a solution but the most important lies in the application of it with its Blockchain platform.

\section{References}

[1] Mélanie Swan, «Blockchain, Blueprint for a new economy », édité par O'Reilly Media, Inc., 1005 Gravenstein Highway North, Sebastopol, CA 95472, Février 2015.

[2] B. Fathi and M. Esmaeilian Department of Economic, Aliguodarz Branch, Islamic Azad University, Aliguodarz, Iran. Evaluation of Value Added Tax (VAT) and Tax Evasion. Published: February 25, 2012.

[3] Erich Kirchler, Boris Maciejovsky, Friedrich Schneider. Social
Representations on Tax Avoidance, Tax Evasion, and Tax Flight: Do Legal Differences Matter? March 2001.

[4] Omar Dib, Kei-Leo Brousmiche, Antoine Durand, Eric Thea, Elyes Ben HamidaIRT SystemX, Paris-Saclay, France. Consortium Blockchains: Overview, Applications and Challenges.

[5] Diego Ongaro and John Ousterhout, Stanford University. In Search of an Understandable Consensus Algorithm; 2013.

[6] Raft Consensus Algorithm; https://www.geeksforgeeks.org/raft-consensus-algorithm/.

[7] Special report, Fight against intra-community VAT fraud: additional actions are required; European Court of Auditors; 2015.

[8] John Clow, Stanford University, jclow@stanford.edu; Zhiling Jiang, Stanford University, zjiang23@stanford.edu; A Byzantine Fault Tolerance Raft.

[9] Christopher Copeland and Hongxia Zhong; Tangaroa: a Byzantine Fault Tolerance Raft.

[10] Elvice DJOMENI KOLOKO, 2008, University of Douala; Taxation of investments and tax optimization case of Cameroon; Professional Master II in applied taxation.

[11] VAT and cryptotechnologies: From apprehension to adoption; Laperriere Edouard, Master's thesis, University of Paris 1, Pathéon Sorbonne, academic year 2017-2018.

[12] Richard T. Ainsworth, Boston University School of Law; Andrew Shact, WP Tax and Treasure; Blockchain (Distributed Ledger Technology) solves VAT fraud, 20 juin, 2016, https://www.bu.edu/law/files/2016/10/BLOCKCHAIN-3.pdf.

[13] Richard T. Ainsworth, Boston University School of Law; Musaad Alwohaibi, University of Florida, Levin College of Law, Students; Mike Cheetham, Independent; Camille Tirand, Organization for Economic Co-Operation and Development (OECD) - Centre for Tax Policy and Administration (CTP); A VATCoin Proposal Following on The 2017 EU VAT.

[14] Muka Samuel, University of Bamenda; Michael Forzeh Fossung, University of Buea; Tax Evasion in Cameroon: Causes and Remedies; 9 August 2019; Research Journal of Finance and Accounting Vol. 10, No. 14, 2019.

[15] Charles Vellutini (Team leader - ECOPA), Georges Casamatta (ECOPA), Léa Bousquet (ECOPA), Grzegorz Poniatowski (CASE); Estimating International Tax Evasion by Individuals; September 2019; European Commission; Taxation papers; Working paper No 76-2019.

[16] Era Dabla-Norris, Mark Gradstein, Fedor Miryugin, and Florian Misch; Productivity and Tax Evasion; November 2019; International Monetary Fund; WP/19/260.

[17] WikiCrea; A diagram to understand the mechanism of the VAT; $\quad$ https://www.creerentreprise.fr/schema-pourcomprendre-mecanisme-tva/; updated on 27 November 2018. 